\title{
Voltammetric determination of trace mercury in chloride media at glassy carbon electrodes modified with polycationic ionomers
}

\author{
Paolo Ugo ${ }^{*}$, Ligia Maria Moretto, Gian Antonio Mazzocchin \\ Department of Physical Chemistry, University of Venice, Calle Larga S. Marta 2137, I-30123 Venice, Italy
}

Received 24 March 1994

\begin{abstract}
The perfluorinated polycationic polymer Tosflex ${ }^{3}$ is used for preparing polymer modified electrodes able to preconcentrate and detect the anionic complex $\mathrm{HgCl}_{4}^{2-}$, which is the prevailing inorganic $\mathrm{Hg}$ (II) species in sea water and other chloride media. The study of the ion-exchange voltammetric behaviour of the tetrachloromercurate(II) complex at Tosflex-modified electrodes indicates the efficient incorporation of the analyte into the polymeric coating to which a remarkable positive shift in the reduction potential of $\mathrm{HgCl}_{4}^{2-}$ to $\mathrm{Hg}^{0}$ is associated. The partition and selectivity coefficient values for the ion-exchange equilibrium involved are calculated from voltammetric data. When using an ion-exchange preconcentration step under open circuit conditions followed by a cyclic voltammetry detection step, a detection limit in the $10^{-8} \mathrm{M}$ range is achieved, the exact figure depending on the scan rate employed. The application of a reducing potential during the preconcentration (i.e., using a mixed ion-exchange + Faradaic preconcentration regime) and the use of differential pulse voltammetry, lower the relevant detection limit by about three orders of magnitude. Results concerning optimization of the experimental parameters as well as lowering of the influence of possible interferents, such as copper and competing anions, are reported. Finally, an analytical procedure for exploiting the peculiar properties of Tosflex-modified electrodes for the determination of mercury in coastal waters samples is proposed and experimentally tested.
\end{abstract}

Keywords: Ion exchange; Voltammetry; Mercury traces; Sea water; Waters

\section{Introduction}

The application of electroanalytical methods for the determination of mercury in chloride media and in sea water have been already studied [1-3], however, some of the main problems connected to this analysis has not been solved yet.

The anodic stripping determination of trace mercury at solid electrodes, such as graphite electrodes is time consuming, requiring a long Faradaic reductive preconcentration step [3]. By using gold as the elec-

\footnotetext{
${ }^{*}$ Corresponding author.
}

trode material [4-6], the achievement of low detection limits is favoured by the formation of a goldmercury amalgam. Unfortunately, for sea water analysis, a medium exchange between the preconcentration and detection steps is required since the stripping step has to be carried out in the absence of chloride, otherwise gold itself is stripped to give soluble $\mathrm{Au}$ (III)-chloride complexes. Such a medium exchange complicates the analysis and is a potential source of error.

Apart from the need to reach low detection limits, other problems in the analysis of trace mercury at solid electrodes arise from the interference caused by 
the presence of other transition metal cations in the sample [7] which are co-plated together with mercury during the Faradaic preconcentration step, giving a variety of intermetallic compounds. In particular, in the quite common case of the presence of copper at concentration level higher than mercury, the formation of solid precipitates, other than the $\mathrm{Hg}-\mathrm{Cu}$ amalgam, is reflected in the appearance of new stripping peaks overlapping with the one relevant to mercury reoxidation.

An alternative approach to improve the applicability of electroanalytical methods to this aim is offered by the use of modified electrodes in which the analyte is preconcentrated by interacting with a suitable modifier immobilized on the electrode surface [8] and a variety of modifiers has been proposed, also to the aim of preconcentrating and determining trace mercury. The proposed methods take advantage of the use of clectrodes modified with zcolites [9], polypyrrole derivatives [10], or different ligands able to coordinate the mercuric cation [11-18].

All these methods are based on the exploitation of interactions between the modifier and the cation $\mathrm{Hg}^{2+}$. However, in sea water and in aqueous media containing chloride at concentration levels higher than $0.15 \mathrm{M}$, the prevailing inorganic mercury species is the anion $\mathrm{HgCl}_{4}^{2-}$ [19] and the use of electrodes modified with anion exchangers seems worth to be explored. Up to now, however, only one paper [20] reports on the determination of mercury at electrodes modified with an anion exchanger, namely carbon paste electrodes modified with Amberlite LA 2. It is worth noting that the use of such a modified electrode requires itself a medium exchange; moreover its sensitivity, although very interesting, is not good enough for applications in sea water.

Recently, a new class of perfluorinated anion exchangers named Tosflex (Tosoh Soda Manufacturing, Kanagawa, Japan) has been used to recast thin polymer films on carbon electrodes [21,22].

As shown by the structural formula

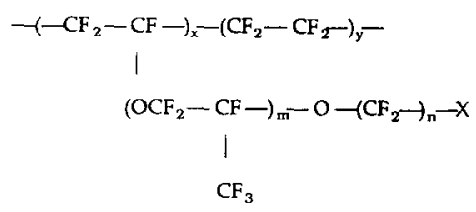

(where $m=0-1, n=1-5$ and $\mathrm{X}=$ anion-exchange unit, including the counter anion) this polymer can be considered as the anion exchanger analogue of Nafion. In the light of recent reports concerning the voltammetric determination of trace electroactive anions preconcentrated via ion exchange at electrodes modified with this $[21,22]$ and similar ionomers [23], in the present study we examine the possibility to employ Tosflex-modified electrodes for determining mercury in chloride containing media and in some marine and lagoon water samples.

\section{Experimental}

\subsection{Chemicals}

All chemicals used were of analytical reagent grade, except those for sea water analysis which were of Suprapur ${ }^{8}$ grade (Merck). Milli-Q water was used throughout to prepare supporting electrolyte solutions which were further purified by flowing through a Chelex 100 column. Aqueous alcoholic solutions (water-methanol-2-propanol, 1:1:1) of Tosflex ${ }^{\circledR}$ IE-SA 48 polymer were prepared from the thick solid membrane, obtained from Tosoh Soda, using the method of Dunsch et al. [21]. The filtered solution had a concentration of about $2.5 \%(\mathrm{w} / \mathrm{v})$.

\subsection{Apparatus and procedures}

All electroanalytical measurements were made at room temperature $\left(22 \pm 1^{\circ} \mathrm{C}\right)$ under a nitrogen atmosphere. A conventional single-compartment cell equipped with a platinum coil counter electrode and a $\mathrm{KCl}$ saturated $\mathrm{Ag} / \mathrm{AgCl}$ reference electrode was employed. The working electrode was a PTFEshrouded glassy carbon disk (area $0.2 \mathrm{~cm}^{2}$ ) polished to a mirror finish with graded alumina powder. The electrode assembly was constructed so that the modified electrode could be used also as a rotating disk electrode. All measurements, except those in natural waters, were performed in $0.5 \mathrm{M} \mathrm{NaCl}-10^{-2} \mathrm{M} \mathrm{HCl}$.

Preliminary electrochemical measurements were carried out with an EG \& G PAR Model 273 programmable potentiostat controlled by a personal computer via EG \& G PAR M270 software. For measurements at ultratrace levels $\left(<10^{-8} \mathrm{M}\right)$ an EG \& G PAR Model 384 was preferred since its responses are characterized by more favorable signal-to-noise ra- 
tios. For experiments at the rotating disk electrode an EG\& G PAR Model 636 was used.

Water samples from the North Adriatic Sea (at $45^{\circ} 18^{\prime} 9^{\prime \prime}$ North and $2^{\circ} 30^{\prime} 5^{\prime \prime}$ East, 8 miles from Venice coast) were sampled in preconditioned bottles at about $50 \mathrm{~cm}$ depth; water samples from the Venice Lagoon (San Marco basin) were sampled with a submersed all-PTFE pump at about $1 \mathrm{~m}$ depth in high tide conditions. After filtration through $0.45-\mu \mathrm{m}$ Millex-HV Millipore membrane, $2 \mathrm{ml} / 1$ of Suprapur hydrochloric acid $(30 \% \mathrm{w} / \mathrm{w})$ were added and incubated at least for $48 \mathrm{~h}$ before analysis. Measurements of mercury in these natural water samples were performed in a clean laboratory, under Class 100 laminar flow hoods, with particular care to avoid mercury contamination from the laboratory environment. Sample bottles and other labware were acid cleaned and conditioned according to usual recommended procedures [24].

Tosflex coated electrodes were prepared by droplet evaporation of $3 \mu \mathrm{l}$ of $2.5 \%(\mathrm{w} / \mathrm{v})$ Tosflex solution deposited on a mirror-polished glassy carbon disk electrode. The evaporation of the solvent was performed in a methanol atmosphere to have a slow evaporation rate. The average value for the thickness of the wet coating, measured with an Alfa Step profilometer (Tencor, Mountain View, CA), was 1.8 $\mu \mathrm{m}$.

\subsection{Calculations}

The distribution coefficient, $k_{\mathrm{D}}$, for the ion-exchange equilibrium

$$
\begin{aligned}
& \left(\mathrm{HgCl}_{4}^{2-}\right)_{\mathrm{s}}+2\left(\mathrm{Cl}^{-}\right)_{\mathrm{p}} \\
& \Leftrightarrow\left(\mathrm{HgCl}_{4}^{2-}\right)_{\mathrm{p}}+2\left(\mathrm{Cl}^{-}\right)_{\mathrm{s}}
\end{aligned}
$$

is given by

$k_{\mathrm{D}}=\left[\mathrm{HgCl}_{4}^{2-}\right]_{\mathrm{p}} /\left[\mathrm{HgCl}_{4}^{2-}\right]_{\mathrm{s}}$

and the selectivity coefficient, $\mathrm{K}_{\mathrm{Cl}^{-}}^{\mathrm{HgCl}_{4}^{2-}}$ was calculated as

$$
\begin{aligned}
K_{\mathrm{Cl}^{-}}^{\mathrm{HgCl}_{4}^{2-}=} & {\left[\mathrm{HgCl}_{4}^{2-}\right]_{\mathrm{p}}\left[\mathrm{Cl}^{-}\right]_{\mathrm{s}}^{2} } \\
& /\left[\mathrm{HgCl}_{4}^{2-}\right]_{\mathrm{s}}\left[\mathrm{Cl}^{-}\right]_{\mathrm{p}}^{2}
\end{aligned}
$$

where the subscripts $p$ and $s$ refer to concentrations in the polymeric coating and in the solution, respectively.

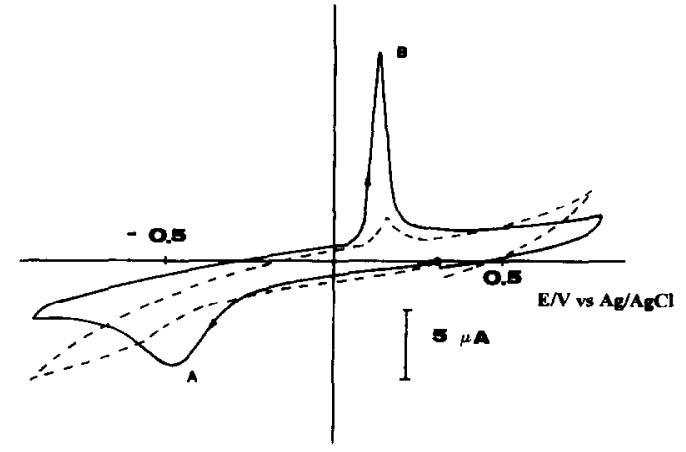

Fig. 1. Cyclic voltammograms of $5 \mu \mathrm{M} \mathrm{HgCl}_{4}^{2-}$ in $0.5 \mathrm{M} \mathrm{NaCl}$, $10^{-2} \mathrm{HCl}$ (solid line) at a Tosflex-modified glassy-carbon electrode; (dashed line) at a bare glassy carbon electrode. Scan rate 5 $\mathrm{mVs}^{-1}$.

\section{Results and discussion}

\subsection{Ion-exchange voltammetric behaviour}

As shown in Fig. 1, when a Tosflex-modified electrode is dipped in a tetrachloromercurate(II) solution, quick incorporation and preconcentration of the $\mathrm{HgCl}_{4}^{2-}$ complex is observed. In fact, both currents relevant to the cathodic peak $A$ and anodic peak $B$ of the cyclic voltammogram of Fig. 1 (full line), which correspond respectively to the reduction of $\mathrm{HgCl}_{4}^{2-}$ to metallic mercury and to its reoxidation at the polymer-electrode interface, are significantly higher than those recorded under the same experimental conditions at a bare glassy carbon electrode (see Fig. 1, dashed line).

As far as peak A is concerned, the comparison between the two voltammetric patterns in Fig. 1 shows also relevant changes both in peak shape and peak potential; in fact at the modified electrode this peak is much sharper and its peak potential is shifted significantly towards potential values less negative than the peak recorded at a bare glassy carbon electrode.

As shown in Fig. 2, an even more dramatic potential shift is observed at a disk electrode rotated at $2000 \mathrm{rpm}$, where a reduction half wave potential of $-0.125 \mathrm{~V}$ is recorded for the modified electrode (full line), with respect to a value of $-0.390 \mathrm{~V}$ for the uncoated electrode (broken line). As expected on the basis of literature reports $[25,26]$, the diffusion controlled limiting current recorded at the modified electrode (at potential values $<-0.500 \mathrm{~V}$ ) is roughly the same as the one observed at the bare electrode, while the current response in the rising portion of the cur- 


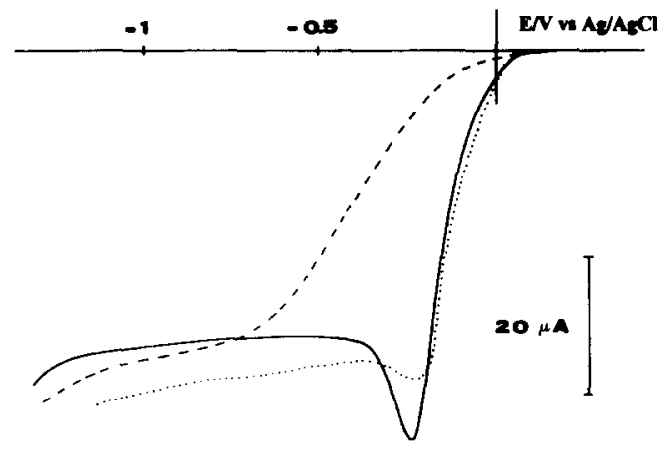

Fig. 2. Current-potential curves for the reduction of $0.1 \mathrm{mM}$ $\mathrm{HgCl}_{4}^{2-}$ at a rotating-disk glassy carbon electrode. (solid line) Tosflex-modified electrode, $2000 \mathrm{rpm}$; ( ...) Tosflex-modified electrode, $2500 \mathrm{rpm}$; (-- -) bare glassy carbon electrode, $2000 \mathrm{rpm}$. Other experimental conditions as in Fig. 1.

rent-potential curve at the modified electrode is peak shaped, even if it tends to merge into the sigmoidal profile on further increase in the rotation rate (see dotted line in Fig. 2).

The relevant positive shift in the reduction potentials, in principle, could be due to the combined influence of the presence of the permselective coating [27] and to the fact that the reduction product is a metal phase.

However, the shape of the voltammograms of Fig. 1 , clearly indicates that slow electron transfer kinetics is influencing the potential of peak $\mathrm{A}$ so preventing the quantitative evaluation of the real weight of these effects to be performed. Anyway, to the aim of the present research, the experimental evidence that at the modified electrode mercury starts to be reduced at far less negative potential values than at the bare electrode has great practical relevance since it is particularly useful for improving the selectivity of the analysis (see below).

The characterization of the ion-exchange behaviour of the modified electrode has been done by analyzing the partition isotherm relevant to the ionexchange equilibrium (1), which is shown in Fig. 3a. This graph was obtained by determining the concentration of $\mathrm{HgCl}_{4}^{2-}$ in the polymeric coating by coulometric integration of the relevant two-electron reduction peak recorded at low scan rate $\left(5 \mathrm{mV} \mathrm{s}^{-1}\right)$ and from the film volume (calculated as the product of the average film thickness times the electrode area). The slope of the initial linear portion of this isotherm [28], allows one to calculate a value of $1.1 \times 10^{4}$ for the distribution coefficient $k_{D}$ (see equation 2) and a value of $5 \times 10^{3}$ for the selectivity coefficient $K_{\mathrm{Cl}^{-}}^{\mathrm{HgCl}_{4}^{2-}}$. These high values indicate a very efficient ion-exchange preconcentration process of $\mathrm{HgCl}_{4}^{2-}$ at the Tosflex modified electrode.

\subsection{Optimization of the method}

As shown in Fig. 3b, both the reduction and reoxidation peaks obtained by cyclic voltammetry at stationary modified electrodes give linear calibration graphs, with a dynamic range extended up to $10^{-5} \mathrm{M}$ which corresponds to the initial linear portion of the partition isotherm in Fig. 3a. However, data obtained from the reoxidation peak are characterized by higher sensitivity and better reproducibility. For this reason all the following discussions will concern only data relevant to exploitation of the reoxidation peak ( $B$ in Fig. 1) for analytical purposes.

Table 1 lists the main statistical data relevant to calibration graphs obtained by changing the mass
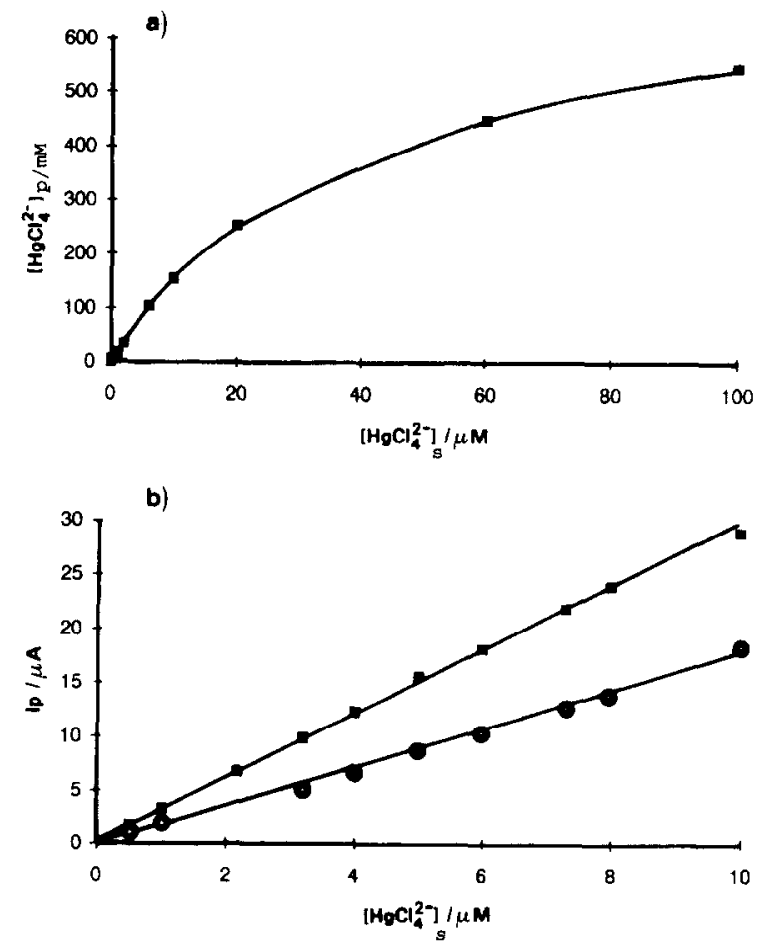

Fig. 3. (a) Partition isotherm for the ion-exchange equilibrium of $\mathrm{HgCl}_{4}^{2-}$ at a Tosflex-modified glassy carbon electrode. (b) Cali-

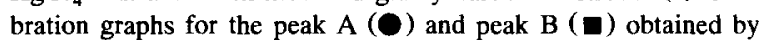
cyclic voltammetry in the same experimental conditions of Fig. 1. 
Table 1

Statistical data relevant to calibration graphs obtained under different experimental conditions

\begin{tabular}{|c|c|c|c|c|c|c|}
\hline Detection technique & Scan parameters & Preconc. ${ }^{a}$ conditions & $m(\mu \mathrm{A} / \mu \mathrm{M})^{\mathrm{b}}$ & Correlation coefficient & $S_{\mathrm{b}}{ }^{\mathrm{c}}$ & $\mathrm{DL}(\mathrm{M})^{\mathrm{e}}$ \\
\hline $\operatorname{LSV}^{\mathrm{f}}$ & $v^{\mathrm{b}}=5 \mathrm{mV} \mathrm{s}^{-1}$ & $0 \mathrm{rpm}$ & 0.983 & 0.999 & 0.023 & $2.3 \times 10^{-8}$ \\
\hline LSV & $v=500 \mathrm{mV} \mathrm{s}^{-1}$ & $0 \mathrm{rpm}$ & 88.78 & 0.994 & 0.930 & $1.1 \times 10^{-8}$ \\
\hline LSV & $v=500 \mathrm{mV} \mathrm{s}^{-1}$ & $2000 \mathrm{rpm}$ & 301.95 & 0.999 & 0.930 & $4.0 \times 10^{-9}$ \\
\hline DPV $\mathrm{g}$ & $-g$ & $2000 \mathrm{rpm}$ & 200.50 & 0.998 & 0.010 & $1.5 \times 10^{-10}$ \\
\hline DPV $^{i}$ & $-g$ & $2000 \mathrm{rpm}$ & 200.50 & 0.998 & $0.003^{d}$ & $4.0 \times 10^{-11}$ \\
\hline
\end{tabular}

${ }^{a}$ Other preconcentration parameters: applied potential $=-0.700 \mathrm{~V}$, reduction time $=5$ min.

${ }^{b} m=$ Slope.

' $S_{\mathrm{b}}=$ Standard deviation of the blank calculated from ten independent background current determinations carried out at freshly prepared modified electrodes.

${ }^{d}$ as ${ }^{c}$, but relevant to ten independent background current determinations carried out at the same regenerated modified electrode.

e $\mathrm{DL}=$ Detection limit, calculated as $3 S_{\mathrm{b}} / \mathrm{m}$.

${ }^{f}$ LSV $=$ Linear sweep voltammetry.

${ }^{\mathrm{g}} \mathrm{DPV}=$ Differential pulse voltammetry with scan parameters: pulse height $=25 \mathrm{mV}$, step time $=0.5 \mathrm{~s}$, scan increment $=5 \mathrm{mV}$, scan rate $=10 \mathrm{mV} \mathrm{s}^{-1}$.

h $v=$ Scan rate.

i Results obtained with repeated use of the same coated electrode.

transport regime during the preconcentration step (stationary vs. rotating modified electrodes) and the electroanalytical technique used in the reoxidationdetection scan (linear sweep vs. differential pulse voltammetry). The preconcentration was carried out by applying at the modified electrode a reduction potential of $-0.700 \mathrm{~V}$ for $5 \mathrm{~min}$ which, in preliminary tests, was found to be long enough to allow the complete reduction to $\mathrm{Hg}^{0}$ of all the incorporated $\mathrm{HgCl}_{4}^{2-}$. As shown by comparing data in the 1 st and 2 nd line of Table 1, the performances offered by linear sweep detection can be improved by increasing the scan rate. The 3rd line indicates that both sensitivity and detection limit of the method are improved by rotating the electrode at $2000 \mathrm{rpm}$ during the preconcentrationreduction step. Under such experimental conditions the reoxidation current is expected to correspond to the addition of two contributions, i.e., the reoxidation current relevant to mercury produced by reducing $\mathrm{HgCl}_{4}^{2-}$ incorporated under ion-exchange equilibrium conditions plus the reoxidation current of mercury generated by reduction of $\mathrm{HgCl}_{4}^{2-}$ coming from the bulk solution because of the rotation of the electrode. These two terms are expected to correspond to the addition of the reoxidation peak current observed at the modified stationary electrode plus the reoxidation peak current observed at a bare glassy carbon electrode rotated at $2000 \mathrm{rpm}$ during the preconcentration-reduction step. However, experiments aiming at verification of this hypothesis have shown that currents measured at a modified electrode rotated during the preconcentration-reduction step are more than two times larger than the summation of the currents recorded at a modified stationary electrode plus currents recorded at an uncoated electrode rotated during the preconcentration-reduction step. Such an increase in the reduction efficiency at rotating disk modified electrodes displays some analogy with similar effects observed by other authors for the electrodeposition of silver and lead at electrodes modified with a mixture of Nafion and crown ethers $[29,30]$. At the present state of knowledge it is difficult to find an explanation for this effect, also because it is not known which influence the formation of metallic deposits has on the charge transfer processes (e.g., electron hopping) which takes place at polymer modified electrodes.

As shown by 4th line of Table 1 , even lower detection limits are achieved by using differential pulse voltammetry as the detection technique and a detection limit of $1.5 \times 10^{-10} \mathrm{M}$ is obtained.

All the above described results, including background noise (6th column in Table 1), refer to measurements carried out using a freshly coated clectrode for each measurement. This was done in order to be sure of getting data free from memory effects, however, these results are negatively affected by the unavoidable irreproducibility of the manual modification procedure of the electrodes adopted here. As far as memory effects are concerned, we have ob- 


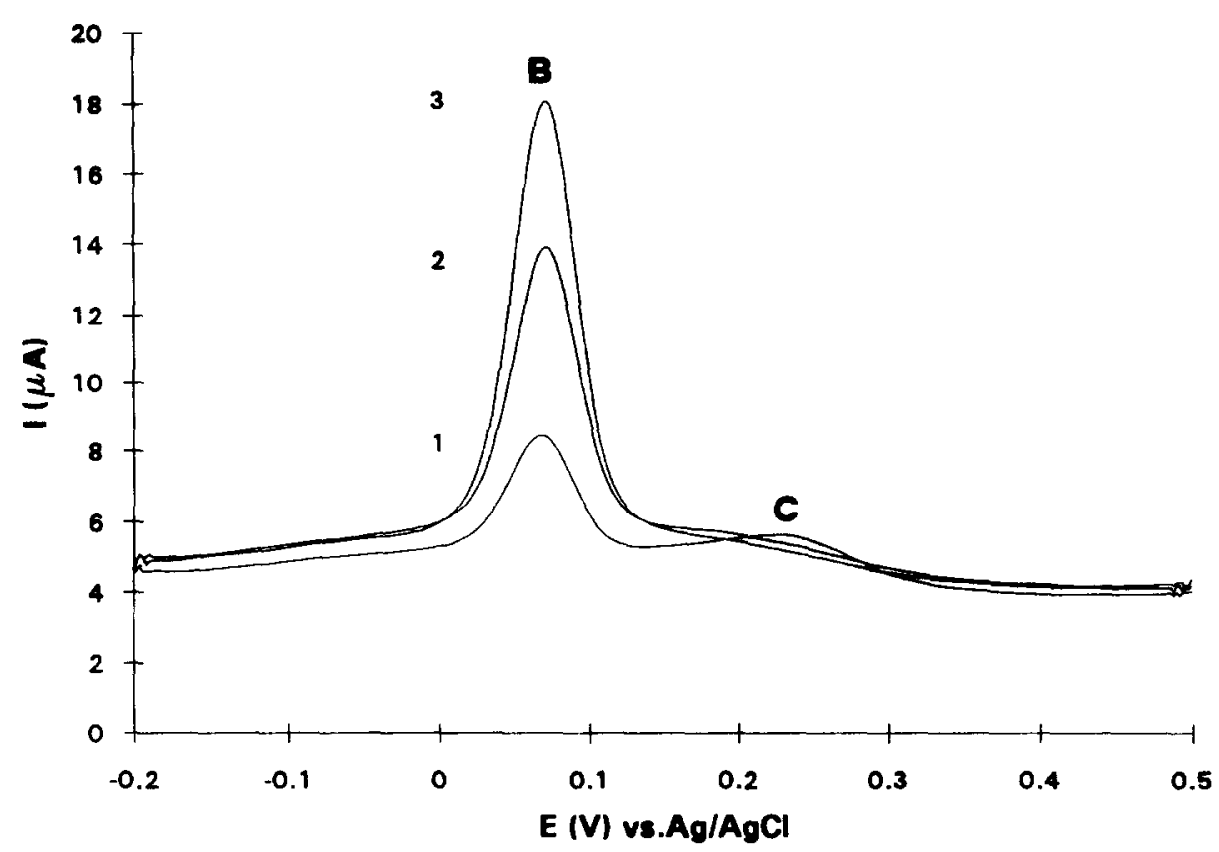

Fig. 4. Differential pulse stripping voltammograms recorded at Tosflex-modified glassy carbon electrode in $0.5 \mu \mathrm{M} \mathrm{Hg}^{2+}$ and $50 \mu \mathrm{M} \mathrm{Cu}{ }^{2+}$. Preconcentration at $-0.200 \mathrm{~V}$ while rotating the electrode at: (1) 0 , (2) 500 , (3) $1500 \mathrm{rpm}$. Stripping at $0 \mathrm{rpm}$, pulse height, $25 \mathrm{mV}$; step time, $0.5 \mathrm{~s}$; scan increment, $5 \mathrm{mV}$; scan rate, $10 \mathrm{mV} \mathrm{s}^{-1}$. Other experimental conditions as in Fig. 1.

served that, at concentration levels lower than $10^{-7}$ $M$ they are not relevant and the same electrode can be reliably exploited for many measurements. Data relevant to a calibration plot obtained at low concentration levels using the same modified electrode for several times, are reported in the last line of Table 1 ; they indicate that this operative procedure has to be preferred for ultratrace analysis since very low detection limits are achieved.

As far as the optimization of the deposition time (dt) is concerned, measurements carried out at $\mathrm{dt}=$ 5-40 min indicate that when $\mathrm{dt}>20 \mathrm{~min}$, both the reproducibility and the dynamic range of the relevant calibration plots worsen progressively, even if the reoxidation current increases. The best compromise is reached at a deposition time in the 5-15 min range, the last deposition time being useful for determining concentration levels around $10^{-10} \mathrm{M}$. For instance, by repeating the DPV measurements of the last line of Table 1 using a dt of $15 \mathrm{~min}$, a detection limit of $1.7 \times 10^{-11} \mathrm{M}$ is obtained.

\subsection{Interferences}

As mentioned in the Introduction, because of the low quantity of mercury deposited, the presence of an excess of copper can causes the co-deposition of different solid and amalgam phases, which are stripped at different potential values giving indented stripping patterns of poor analytical utility.

One way to decrease the effect of such an interference is to carry out mercury electrodeposition at potential values as less negative as possible, i.e., where no metallic phase other than mercury is deposited. At the modified electrode, this can be done thanks to the anticipating effect that the T'osflex coating causes on the reduction potential of $\mathrm{HgCl}_{4}^{2-}$ (see first paragraph).

By applying a potential of $-0.200 \mathrm{~V}$ at the modified electrode during the preconcentration-reduction step, the stripping pattern shown in Fig. 4, line 1, is recorded. Peak $\mathrm{B}$ corresponds to the reoxidation of electrodeposited $\mathrm{Hg}^{\mathrm{O}}$ while peak $\mathrm{C}$, located at 0.230 $\mathrm{V}$, corresponds to the one-electron reoxidation of an anionic cuprous complex, likely $\mathrm{CuCl}_{2}^{-}$, electrogenerated by the one electron reduction of $\mathrm{Cu}^{2+}$ in chloride containing media and preconcentrated at the Tosflex modified electrode [22]. These evidences confirm that at $-0.200 \mathrm{~V}$ only one metallic phase, i.e., $\mathrm{Hg}^{0}$, is deposited. The fact that the peak current ratio $I_{\mathrm{p}}(\mathrm{B}) / I_{\mathrm{p}}(\mathrm{C})$ is much higher than the solution 
concentration ratio of the relevant ions, indicates that the method has a higher sensitivity for mercury than for copper.

Such a specific sensing capacity can be further improved by using a rotating disc modified electrode instead of a static one. As shown in Fig. 4, lines 2-3, the rotation of the electrode during the electrodeposition improves the selectivity of the method toward $\mathrm{Hg}$ detection: in fact, after rotation, the mercury reoxidation peak increases dramatically, while the $\mathrm{Cu}(\mathrm{I}) \mathrm{re}$ oxidation peak $\mathrm{C}$ lowers. This effect is explained by the fact that copper, which is preconcentrated in the form of an anionic complex [22], can diffuse out of the coating, while mercury, which is preconcentrated in its metallic form, cannot. The driving force for the escape of copper(I) complex from the coating lies in the fact that the bulk solution concentration of this species is zero, since it has been electrogenerated only at the polymer coating interface.

In the presence of an excess of copper, we observed that the performances of the modified electrode for ultratrace mercury analysis are improved by preceding the measurement with an activation step of $5 \mathrm{~min}$ at $-0.700 \mathrm{~V}$ followed by an oxidation scan from $-0.200 \mathrm{~V}$ to $0.500 \mathrm{~V}$; this reoxidation scan is repeated up to complete disappearance of all the stripping peaks eventually observed. After this, the electroreduction of mercury at $-0.200 \mathrm{~V}$ is carried out for $10 \mathrm{~min}$ at the "activated" modified electrode followed finally by the "true" detection scan. In this way a linear calibration plot is again obtained and the relevant detection limit is now $2.1 \times 10^{-11} \mathrm{M}$. This activation probably microscopically cleans the electrode surface making it more apt for mercury nucleation during the preconcentration step.

No interference with the preconcentration at $-0.200 \mathrm{~V}$ comes from the presence in solution of other transition metal cations such as $\mathrm{Zn}^{2+}, \mathrm{Cd}^{2+}$ and $\mathrm{Pb}^{2+}$, even when they are in a 100 time excess with respect to mercury. As far as the effect of competing anions is concerned, in principle, some concern could come from $\mathrm{SO}_{4}^{2-}$, which in sea water is present at concentrations of about $0.03 \mathrm{M}$ [31]. Experiments carried out in the presence of increasing amounts of $\mathrm{SO}_{4}^{2-}$, while keeping $\mathrm{Cl}^{-}$constant at $0.5 \mathrm{M}$, indicate that the presence of sulphate lowers the reoxidation peak of mercury only when $\mathrm{SO}_{4}^{2-}$ is present in amounts larger than $0.1 \mathrm{M}$, i.e., at concentration values higher than those typical for sea water.

\subsection{Determination of mercury in coastal sea water samples}

On the basis of the results reported above, Tosflex modified electrodes has been employed for the analysis of coastal sea water samples by adopting the following procedure:

(1) ion-exchange equilibration of the rotating-disk modified electrode for $5 \mathrm{~min}$ at $2000 \mathrm{rpm}$ under open circuit conditions;

(2) deposition at $-0.200 \mathrm{~V}$, rotation at $2000 \mathrm{rpm}$ for $10 \mathrm{~min}$ for lagoon water and for $15 \mathrm{~min}$ for sea water;

(3) differential pulse detection of the incorporated anion, no rotation (for other experimental parameters see Fig. 5, legend).

All steps are carried out directly in the sample solution. The concentration of mercury was quantified by standard additions (see Fig. 5, insets).

Before each set of measurements, corresponding to the sample analysis and relevant standard additions, the modified electrode has been activated directly into the sample solution as described above.

The relevant mercury concentration mean values of five independent determinations ( \pm standard deviation) are $1.6( \pm 0.5) \times 10^{-10} \mathrm{M}$ and $4.2( \pm 1.2) \times$ $10^{-10} \mathrm{M}$ for the North Adriatic Sea sample and Venice Lagoon sample, respectively. It is worth pointing out that these data are aimed mainly to verify the applicability of the proposed method to real samples and do not want to assess what is the "true" concentration level of mercury in these waters, such a level being inferable only as the result of a detailed study specifically devoted to this aim. In any case, the evidence that the above reported data indicate a 2.6 fold increase in mercury concentration when passing from sea water to lagoon water agrees with the trend observed also for other heavy metals (e.g., lead [32]) and is probably due to anthropogenic input of pollutants into the lagoon from the city of Venice and the neighbouring industrial area of Porto Marghera. The increase in concentration of heavy metals from sea to lagoon can be inferred also from the evidence that in the lagoon water voltammogram (Fig. 5a) the shoulder at about $0.230 \mathrm{~V}$, relevant to copper interference, 

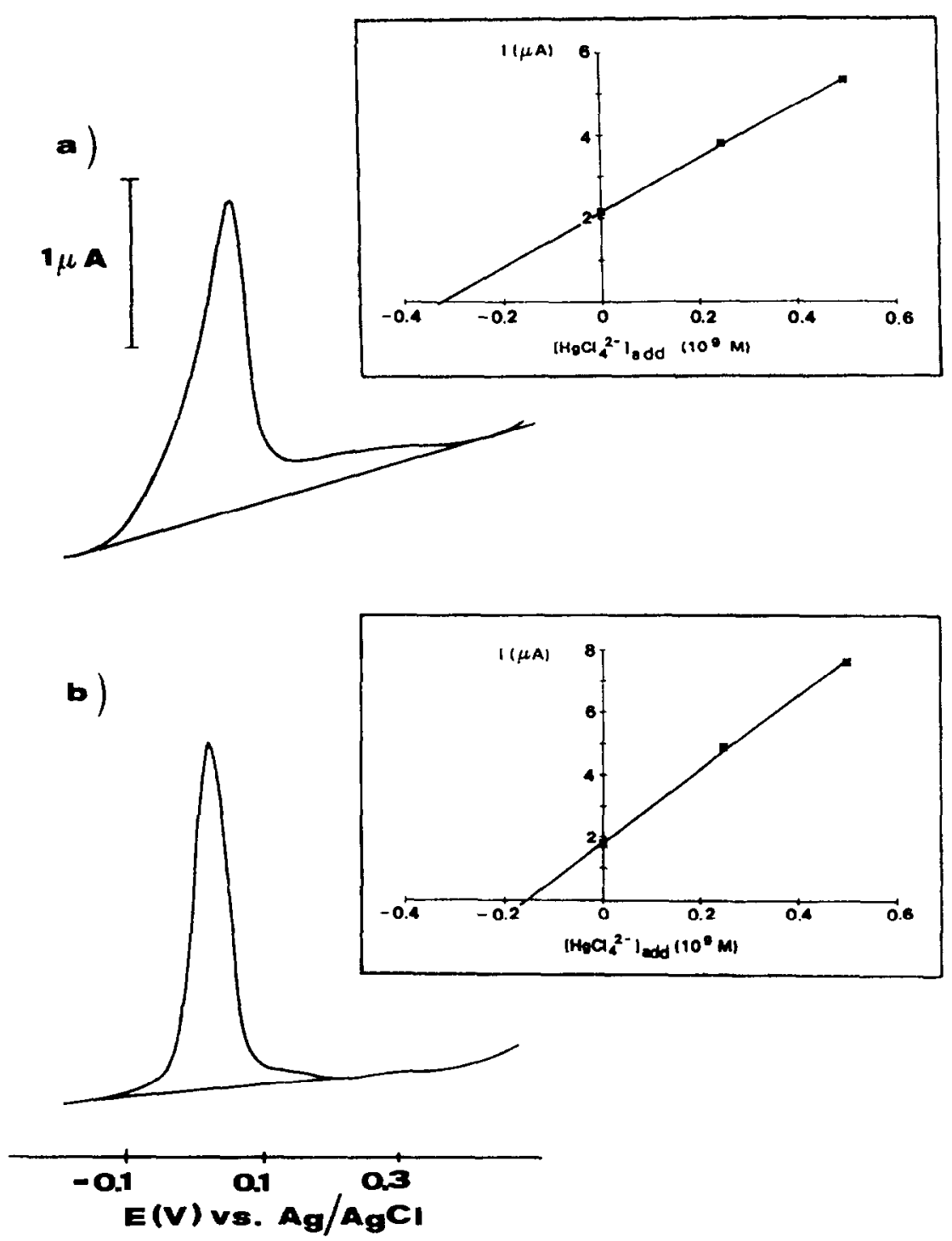

Fig. 5. Differential pulse stripping voltammograms for samples of coastal marine waters: (a) Venice Lagoon sample; (b) North Adriatic sea sample. Ion-exchange preconcentration step: $5 \mathrm{~min}$ at $2000 \mathrm{rpm}$ in open circuit conditions; reduction step at $-0.200 \mathrm{~V}$ at $2000 \mathrm{rpm}$ for 10 min (a) and for $15 \mathrm{~min}$ (b); stripping at $0 \mathrm{rpm}$, pulse height, $25 \mathrm{mV}$; step time, $0.5 \mathrm{~s}$; scan increment, $5 \mathrm{mV}$; scan rate, $10 \mathrm{mV} \mathrm{s}{ }^{-1}$. Insets: standard addition graphs where the subscript 'add' indicates the amount of $\mathrm{HgCl}_{4}^{2-}$ added to the sample.

is more pronounced than in the case of the sea water sample (Fig. 5b).

\section{Conclusions}

The utility of Tosflex modified electrodes for trace mercury analysis in the $10^{-8}-10^{-11} \mathrm{M}$ concentration range in chloride containing media and in sea water is evident from the above results. The presence of the polymeric coating has a dramatic effect for improving the selectivity and reproducibility of the preconcentration step, as well as to keep its time duration within a reasonable range $(15-20 \mathrm{~min})$. Moreover, the proposed method does not require any medium exchange nor the use of a complex experimental apparatus.

New aspects in the behaviour of ion-exchanger modified electrodes incorporating very low concen- 
tration levels of electroactive species and/or their metallic reduction products are also described. For instance, remarkable anticipation of reduction potentials and unusual increase in the amount of deposited metal related to rotation of the modified electrode have been observed.

In the present study some these effects have been exploited for optimizing the analytical performances of the Tosflex-modified electrode, however, further detailed studies are necessary to understand their full physico-chemical significance.

\section{Acknowledgements}

We wish to thank Mr. D. Rudello for technical assistance and Prof. G. Capodaglio for suggestions for the sampling and analysis of marine waters. This work was supported by MURST (Rome) and by Project "Sistema Lagunare Veneziano". L.M.M. was the grateful recipient of a grant from CAPES and IPEN/CNEN, Brazil. The use of the clean laboratory facility for ultratrace analysis was made possible thanks to the Group for Environmental Analytical Chemistry, Department of Environmental Sciences of the University of Venice.

\section{References}

[1] Y. Israel, Anal. Chem., 31 (1959) 1473.

[2] L. Luong and F. Vydra, J. Electroanal. Chem., 50 (1974) 379.

[3] R. Fukay and L. Huynh-Ngoc, Anal. Chim. Acta, 83 (1976) 375.

[4] L. Sipos, P. Valenta, H.W. Nurnberg and M. Branica, J. Electroanal. Chem., 77 (1977) 263.

[5] L. Sipos, H.W. Nurnberg, P. Valenta and M. Branica, Anal. Chim. Acta, 115 (1980) 25.

[6] I. Gustavsson, J. Electroanal. Chem., 214 (1986) 31.
[7] J. Wang, Stripping Analysis, Principles, Instrumentation and Applications, VCH, Weinheim, 1985, Chap. 4.

[8] J. Wang, in A.J. Bard (Ed.), Electroanalytical Chemistry, Vol. 16, Marcel Dekker, New York, 1989.

[9] P. Hernandez, E. Alda and L. Hernandez, Frezenius' Z. Anal. Chem., 327 (1987) 676.

[10] M.D. Imisides and G.G. Wallace, J. Electroanal. Chem., 246 (1988) 181.

[11] J. Labuda and V. Plaskon, Anal. Chim. Acta, 228 (1990) 259.

[12] Z. Navratilova, Electroanalysis, 3 (1991) 799.

[13] K.-Z. Liu, Q.-C. Wu and H.-L. Liu, Analyst, 115 (1990) 259.

[14] I. Svancara, K. Vytras, C. Hua and M.R. Smyth, Talanta, 39 (1992) 391.

[15] Z. Gao, P. Li and Z. Zhao, Microchem. J., 43 (1991) 121.

[16] J. Wang and M. Bonakdar, Talanta, 35 (1988) 277.

[17] S.K. Cha, B.K. Ahn, J.-U. Hwang and H.D. Abruña, Anal. Chem., 65 (1993) 1564.

[18] I. Turyan and D. Mandler, Nature, 362 (1993) 703.

[19] J.W. Moore and S. Ramamoorthy, Heavy Metals in Natural Watcrs, Springer Verlag, Ncw York, 1984, Chap. 7.

[20] X. Cai, K. Kalcher, W. Diewald, C. Neuhold and R.J. Magee, Frezenius' Z. Anal. Chem., 345 (1993) 25.

[21] L. Dunsch, L. Kavan and J. Weber, J. Electroanal. Chem., 280 (1990) 313.

[22] P. Ugo, L.M. Moretto and G.A. Mazzocchin, Anal. Chim. Acta, 273 (1993) 229.

[23] N. Oyama, T. Oshaka and T. Okjima, Anal. Chem., 58 (1986) 979.

[24] L. Mart, Frezenius' Z. Anal. Chem., 296 (1979) 350.

[25] K. Shigehara, N. Oyama and F.C. Anson, Inorg. Chem., 20 (1981) 518.

[26] F.C. Anson, J.M. Saveant and K. Shigehara, J. Phys. Chem., 87 (1983) 214

[27] R. Naegeli, J. Redepenning and F.C. Anson, J. Phys. Chem., 90 (1986) 6227.

[28] N.M. Szentirmay and C.R. Martin, Anal. Chem., 56 (1984) 1898.

[29] S. Dong and Y. Wang, Anal. Chim. Acta, 212 (1988) 341.

[30] S. Dong and Y. Wang, Talanta, 35 (1988) 819.

[31] W. Stumm and J.J. Morgan, Aquatic Chemistry, 2nd edn., Wiley, New York, 1981, Chap. 9.

[32] G. Capodaglio, G. Scarponi and P. Cescon, in A.A. Oriu (Ed.), Environmental Contamination, CEP Consultants, Edinburgh, 1988 , p. 405. 